\title{
PENGEMBANGAN DUSUN BARAN, TLOGOWARU, KEDUNGKANDANG SEBAGAI KAMPUNG WISATA TOPENG DI KOTA MALANG
}

\author{
A.Tutut Subadyo \\ Fakultas Teknik Universitas Merdeka Malang \\ e-mail : tutut.subadyo@unmer.ac.id
}

\begin{abstract}
Abstrak
Kota Malang sebagai tujuan wisata memiliki sejumlah kampung wisata, salah satunya adalah kampung wisata Topeng, di Dusun Baran, Kelurahan Tlogowaru, Kecamatan Kedungkandang. Kampung tersebut merupakan salah satu penerapan program Desaku Menanti dari Direktorat Jenderal Rehabilitasi Sosial, Kementerian Sosial Republik Indonesia untuk merehabilitasi anak jalanan, gelandangan, dan pengemis. Program ini dimulai pada bulan November 2016, dimana Kemensos telah memberikan bantuan dana untuk pembangunan 40 rumah. Kampung seluas $5000 \mathrm{~m} 2$ dikembangkan bersama komunitas masyarakat seperti Malang Struddle, Amazing Malang, Lingkar Malang dan lain-lain. Pembangunan rumah dan fasilitas lainnya melalui swadaya dan secara gotong royong oleh warga kampung ini. Dalam mendukung terwujudnya rencana kampung wisata budaya topeng malangan yang prospektif, perlu mendapatkan bantuan pendampingan dan kemitraan dalam pengembangannya melalui desain spatial arsitektural dengan pendekatan participatory approach. Keunikan dan kekayaan budaya yang ada di kampung topeng tersebut dikembangkan dan dilestarikan melalui strategi wisata budaya. Pengembangan dan strategi pembangunannya difokuskan pada aspek fisik arsitektural berbasis budaya sehingga kultur topeng malangan yang ada di kampung tersebut dapat lestari dan berkelanjutan. Hasil desain pengembangan dengan sejumlah fasilitas-fasilitas tambahan dan pendukung eksistensi kampung topeng ini dapat dijadikan role model untuk kampung-kampung tematik berbasis budaya yang diproyeksikan menjadi destinasi wisata.
\end{abstract}

Kata Kunci : barakan, kampung, topeng, wisata budaya

\section{PENDAHULUAN}

Dalam rangka mengentaskan kemiskinan, Kementerian Sosial Republik Indonesia sejak tahun 2014 meluncurkan program "Desaku Menanti". Program tersebut diterapkan di beberapa kota besar di Indonesia, dan Kota Malang terpilih sebagai pilot project city nya. Desa yang menjadi lokusnya adalah Desa Argomulyo, tepatnya di Dusun Beran, Tlogowaru, Kecamatan Kedung Kandang, Kota Malang - dibangun kampung baru untuk menampung anak jalanan (Anjal), gelandangan dan pengemis (Gepeng) di Kota Malang yang banyak berkerumun dan mangkal di perempatan jalan dan di tempattempat publik lainnya.

Kampung tersebut oleh Dinas Sosial Kota Malang dijadikan wadah memukimkan para Anjal dan Gepeng agar mereka dapat menjadi warga yang bermartabat dengan diberikan tempat yang layak serta didampingi dalam melakukan proses bermukim dengan aktivitas yang dapat melakukan peningkatan taraf hidup serta memajukan pendapatannya. Proses pemukiman mereka dilakukan dengan cara persuasif, melalui seleksi ini agar para Anjal dan Gepeng berkomitmen untuk berbenah diri dan tidak kembali mengemis dijalan. Pembangunan hunian di kampung tersebut dibiayai oleh Kementerian Sosial RI, sementara pembangunan fasilitas merupakan bantuan dari donator dari berbagi pihak dan Community Social Responsibility (CSR).

Guna merangsang dan memotivasi penghuninya (yang berasal dari para Anjal dan Gepeng) dilakukan pendampingan dengan membuat tema kampungnya sebagai kampung topeng malangan. Tema ini dipilih dengan alas an bahwa salah satu ikon dan identitas kota Malang yang bisa dengan mudah diapresiasi oleh masyarakat adalah keberadaan kesenian dan budaya topeng malangan. Meskipun tema ini masih sangat premature dalam implementasinya, namun sejumlah potensi masih sangat banyak yang bisa ditingkatkan. Sekait dengan kondisi dan permasalahan tersebut maka diperlukan pengelaborasian tema tersebut dalam mengoptimalisasi dan diversifikasi dari eksistensi kampung tersebut menjadi sebuah destinasi wisata baru dengan sejumlah produk wisatanya. 
Pendampingan pengembangan kampung dilakukan melalui teknik participatory design, dimana warga diajak secara bersama-sama mengembangkan potensi yang ada (baik fisik maupun non fisik) serta meminimalisasi kendalanya, sehingga dapat terwujud lingkungan binaaan yang accesabel dan berpeluang menjadi lokus dari objek wisata budaya. Lanskap budaya pada desain tersebut dieksplorasi dari potensi wilayah geografisnya, termasuk sumber daya alam dan budaya serta makhluk hidup lainnya.

Dalam pengembangan Kampung Topeng Malangan di Dusun Beran, Kelurahan Tlogowaru, Kecamatan Kedungkandang, Kota Malang ini, landasan konseptual teoritik yang digunakan adalah pendekatan yang bersifat bottom up, dimana warga masyarakat dimotivasi keterlibatannya sejak proses perencanaan, perancangan, dan pelaksanaannya sehingga hasil yang dicapai dapat menjadikan kampung tersebut sebagai kampung wisata dengan nuansa budaya topeng malangan.

\section{METODE KEGIATAN}

Metode kegiatan dalam proses pendampingan pengembangan kampung topeng sebagai kampung wisata dilakukan melalui teknik participatory design yakni merancang dengan pendekatan secara "bottomup" dimana aspirasi yang muncul dari bawah dijadikan dasar pengambilan keputusan. Dalam proses desain pengembangan kampung topeng ini, konsep "bottom up" dikedepankan, di mana masyarakat dijadikan subyek pembangunan dan bukan sebagai obyek. Desain pengembangan kampung Topeng didasarkan pada aspirasi masyarakat yang ditampung dan diolah sebagai acuan dalam proses perancangan. Dengan melihat aspirasi masyarakat tersebut kebutuhan masyarakat akan suatu teknologi dapat terpenuhi dan tidak berseberangan dengan keinginan masyarakat, sehingga masyarakat merasa memiliki dan berusaha memeliharanya. Dalam upaya menjadikan masyarakat sebagai subyek, perlu adanya suatu pemberdayaan dan penyiapan masyarakat yang biasa di kenal dengan konsep "Community Based Development" atau "Participantry Approach". Semangat untuk memberdayakan masyarakat dan memberikan iklim yang kondusif bagi partisipasi dikedepankan.

Perangkat kelurahan Tlogowaru, serta pihak swasta dan warga masyarakat Dusun Baran, secara bersama-sama diajak menyiapkan dan merencanakan, melaksanakan serta mengendalikan pengembangan kampung tersebut sebagai kampung wisata topeng. Dengan demikian terjadi interaksi kepentingan dan kebutuhan yang dapat tertampung dalam satu wadah. Di sini aparat Kelurahan Tlogowaru dituntut aktif melakukan sosialisasi program pengembangan kampung Topeng dan pemberdayaan masyarakat, dan juga mengajak swasta untuk ikut membantu proses dan implementasinya.

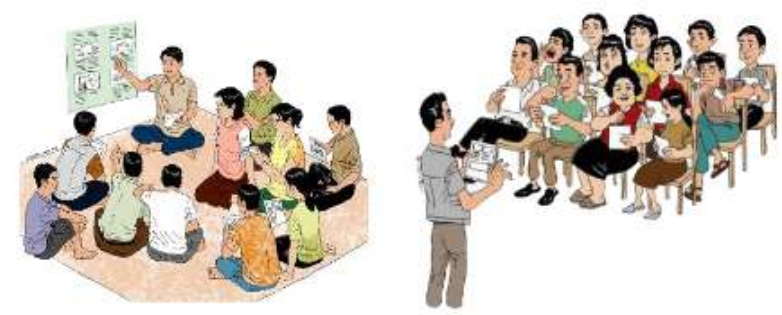

Gambar. 1. Rembug warga dilakukan untuk memperkenalkan program pengembangan kampong wisata topeng kepada masyarakat.

Dalam pengembangan desain Kampung Wisata Topeng di Dusun Baran, Kelurahan Tlogowaru secara aktif diupayakan agar seluruh proses desain sampai kepada stakeholder, serta mengupayakan agar proses keikutsertaan masyarakat dalam semua level (lewat rembug warga) terlaksana secara berkesinambungan. Menurut Subadyo (2011), analisis terhadap tapak dilakukan untuk memgetahui potensi dan kendalanya yang digunakan untuk menunjang rencana kampong wisata budaya topeng di Dusun Baran, Kelurahan Tlogowaru, Kecamatan Kedungkandang, Kota Malang, ditinjau dari tiga aspek yaitu kampung wisata budaya, kepariwisataan, dan aspek sosial budaya (Chiara, 1994; Wulandari, 2002).

Penentukan batas wilayah yang akan dikembangkan sebagai wilayah kampung wisata budaya topeng, ditetapkan secara deskriptif dan spasial, dengan kriteria komunitas topeng, artifak budaya topeng, suasana budaya topeng, aksesibilitas, dan visibilitas visualnya. Sedangkan analisis aspek kepariwisataan terdiri dari analisis potensi lanskap, objek dan atraksi wisata, fasilitas 
pendukung serta aksesibilitas, guna penentuan ruang dan fasilitas wisata di Dusun Baran. Melalui metode overlay dihasilkan zona wisata budaya topeng, dan rencana aktifitas wisata, fasilitas pendukung wisata dan jalur wisata di Dusun Beran, Kelurahan Tlogowaru, Kecamatan Kedungkandang, Kota Malang.
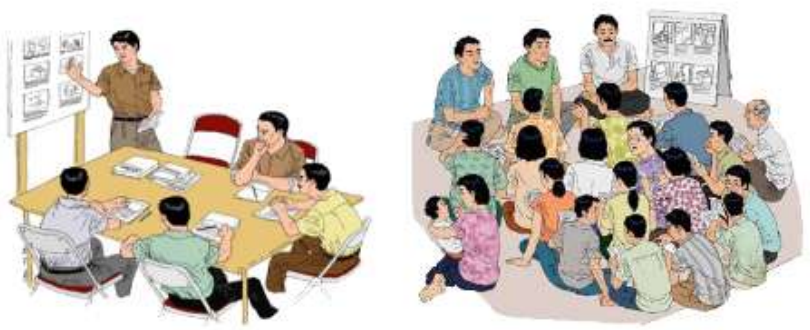

Gambar. 2. Penyusunan desain pengembangan Dusun Baran, Tlogowaru sebagai Kampung Wisata Topeng Malangan didasarkan pada hasil identifikasi serta memuat usulan-usulan kegiatan berdasarkan rembug warga yang sudah mendapat kesepakatan dalam musyawarat desa

Analisis aspek sosial budaya dilakukan untuk mengetahui pengetahuan masyarakat terhadap keadaan tapak, serta kesiapan masyarakat sebagai destinasi wisata budaya di Kota Malang. Hasilnya ditulis secara deskriptif dan tabular (Nurisyah, 2001; Subadyo, 2011) untuk menjelaskan kondisi sosial budaya masyarakat dan persepsi mereka terhadap pengembangannya tapak sebagai wisata sejarah budaya topeng malang. Hasil yang diperoleh dari tahap analisis dikembangkan sebagai masukan untuk mendapatkan hasil perencanaan yang sesuai dengan tujuan yang diinginkan. Pada tahap ini dibuat konsep dasar dan konsep pengembangan kampung wisata budaya topeng malangan.

\section{HASIL DAN PEMBAHASAN}

Berdasarkan kondisi rona lingkungan awal dan hasil observasi lapangan maka pengembangan desain kampung wisata Dusun Baran sebagai kampung topeng ini menggunakan konsep dasar dari ekspresi topeng malangan yang memadukan unsur feminimisme dengan konsep kesetangkupan, yang bermakna sebagai lambang cinta dan kasih sayang. Konsep pengembangan yang digagas memadukan alur penyajian topeng malangan dengan simbolsimbol yang terdapat pada karakter topeng malangan. Dimana makna dari sebuah topeng menjadi suatu simbol yang kerap kali digunakan oleh manusia untuk menutupi atau mengekspresikan apa yang ada didalam hati mereka. Pengembangan kampung wisata diperlukan untuk membuat daya tarik masyarakat untuk mengunjungi kampung wisata, salah satu upaya yang dilakukan dengan menata area yang dianggap kurang optimal.

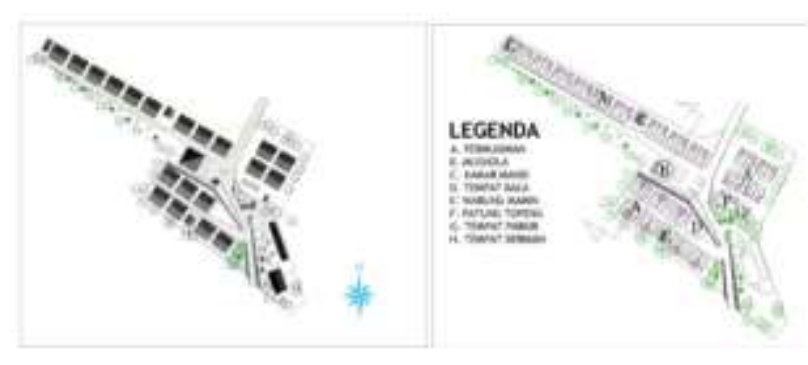

Gambar. 3. Eksisting Site Plan \& Layout Plan Kampung Topeng Beran, Tlogowaru, Kota Malang

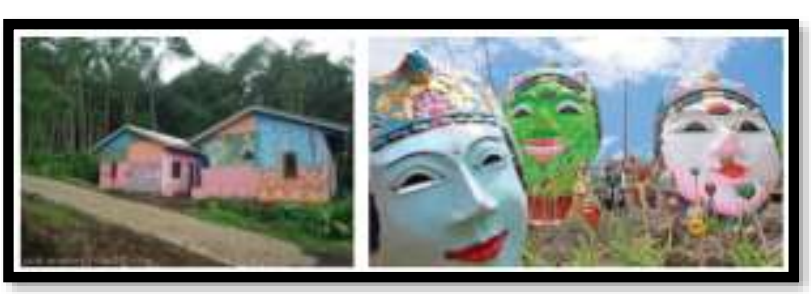

Gambar 4. Keberadaan Topeng Panji sebagai Art Work Ruang Penerima

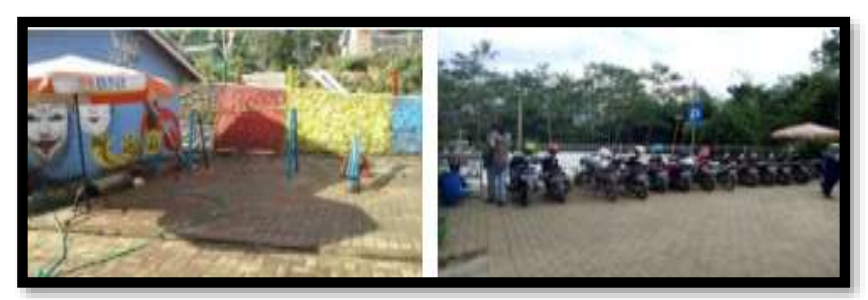

Gambar. 5. Ruang Sosial \& Ruang Penerima di Kampung Wisata Topeng Beran, Tlogowaru, Kota Malang

\section{Pengembangan Ruang}

Pengembangan kampung wisata topeng di Dusun Baran, Kelurahan Tlogowaru, Kecamatan Kedungkandang, Kota Malang diperlukan untuk menjadikannya sebagai destinasi wisata kultural baru, yang secara eksisting penataannya hanya dirancang untuk hunian resettlement bagi Anjal dan Gepeng. Kondisi ini yang melatarbelakangi kekurang optimalannya sebagai subjek dan objek wisata. Hal lain yang juga menjadi kendala adalah akses sirkulasinya dimana diperlukan penambahan area 
lahan untuk membuat sirkulasinya yang terhubung dengan kawasan lainnya. Demikian halnya dengan keterbatasan ruang public khususnya lahan parkir sebagai introduction space.

Untuk membuat kesan dan nuansa topeng malangan semakin terasa maka rancangan Jalur wisata budaya menggunakan alur cerita pementasan tari topeng malangan, dengan pembagian area dimulai dari kampung wisata gerbang masuk hingga area service dengan urutan sebagai berikut (Subadyo, 2011):

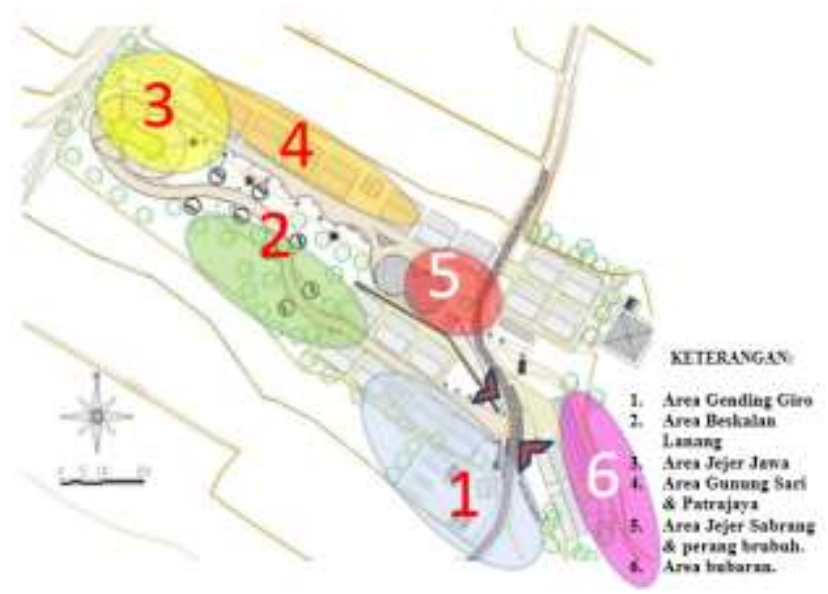

Gambar 6. Desain Pengembangan Kampung WisataTopeng Baran Tlogowaru Kota Malang

Desain pengembangan kampung wisata topeng di Dusun Beran, Kelurahan Tlogowaru, Kecamatan Kedungkandang di bagi mejadi 6 zona, yakni : (1) zona area gending giro, (2) zona area beskalan lanang, (3) Zona area jejer jawa, (4) zona area gunungsari \& patrajaya, (5) zona area jejer sabrang \& perang brubuh, dan (6) zona area bubaran. Rancangan ruang diselaraskan dengan kondisi eksisting, dimana setiap pergantian area (zona) ditandai dengan perubahan fasilitas yang ada. Penciptaan fasilitas didesain dibuat secara berpasangan untuk memberikan kesan kesetangkupan.

Perancangan kampung wisata topeng ini menggunakan scenario alur pertunjukan topeng yang dimulai dari zona gending giro. Area ini merupakan area penerimaan dari kampung wisata topeng, yang berada di bagian selatan tapak yang berada di sisi kiri jalan. Dari area penerimaan pengunjung akan memasuki area transisi yang dibuat kontras dengan menonjolkan nuansa alami yang berupa taman, dengan penambahan 8 buah area sitting group yang dirancang sebagai tempat pemberhentian sementara. Selanjutnya terdapat area sanggar tari \& workshop yang terletak di ujung tapak bagian barat laut.

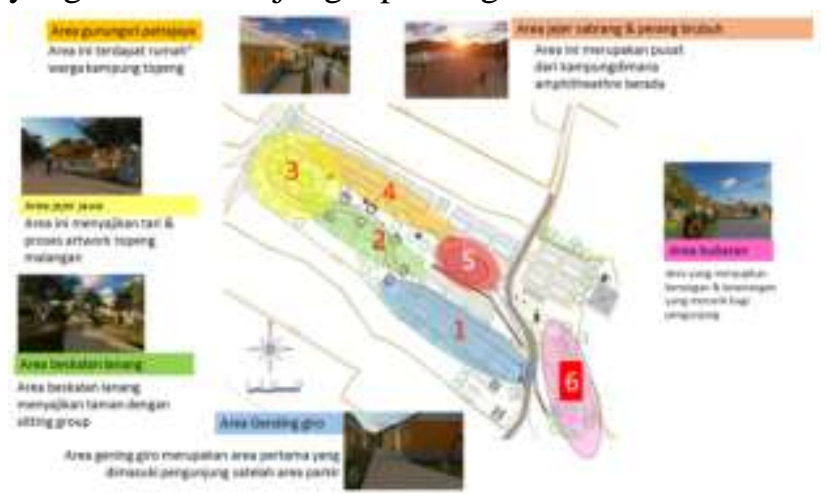

Gambar 7. Desain sequence - sequence pada setiap zona sebagai jalur interpretasi wisata

Area gending giro merupakan area yang pertama kali dilalui ketika memasuki kampung wisata topeng ini, di area ini pengunjung diarahkan menuju area beskalan lanang dengan menggunakan batu pengarah, di area ini pengunjung akan menemui beberapa tempat singgah sementara berupa sitting group, lalu masuk ke area jejer jawa yang memiliki fasilitas sanggar tari \& workshop topeng. Sanggar tari \& workshop topeng merupakan salah satu sarana tempat bertemunya masyarakat kampung topeng dengan wisatawan. Bangunan sanggar tari \& workshop dirancang sebaik mungkin dengan mempertimbangkan aspek kenyamanan \& kemananan penggunanya dengan tidak mengesampingkan nuansa \& suasana topeng malangan

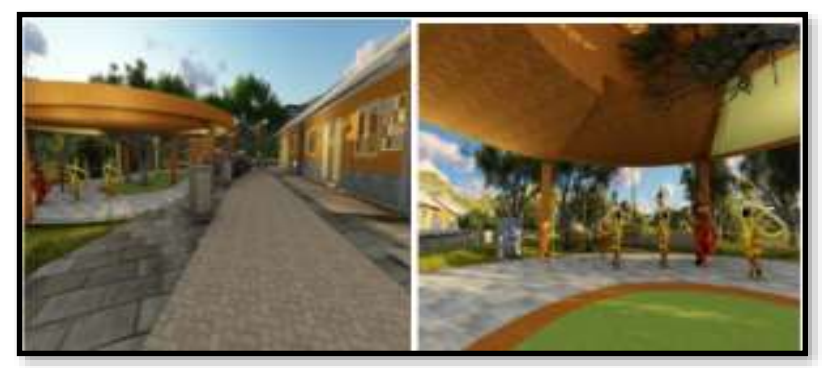

Gambar 8. Korelasi bangunan rumah warga dengan area Sanggar Tari

Desain bangunan sanggar tari yang berbentuk angka 8 (delapan), dianalogikan sebagai alat musik bonang dalam orkestrasi gamelan jawa untuk mempertunjukkan gending giro, bentukan ini 
dieksplorasi dari 2 buah lingkaran, dimana bentuk ini mengadopsi konsep kesetangkupan dari topeng malangan. Bentukan bangunan dibuat terbuka agar pengunjung dapat melihat aktivitas di dalamnya. Desain sanggar tari \& workshop topeng mengambil bentukan dasar dua buah lingkaran yang masing masing memiliki panjang 6 meter yang mengekspresikan 6 karkter utama tokoh pewayangan topeng malangan. Agar bangunan lebih terlihat kreatif maka bentuk dasar di interseksikan, sehingga memiliki bentuk yang selaras dengan jalur sirkulasi.
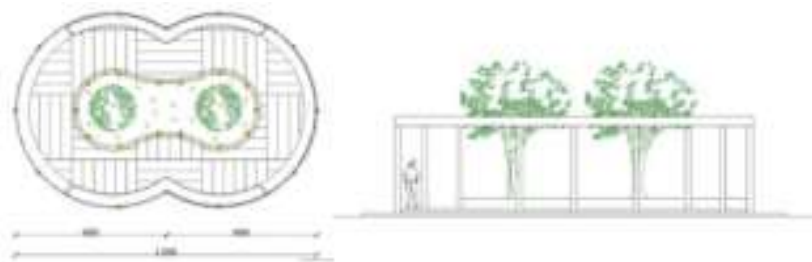

Gambar 9. Denah \& Tampak Art Work Sanggar Tari \& Workshop Topeng

Bagian tengah bangunan Sanggar Tari dibiarkan terbuka agar memiliki kesan lebih menyatu dengan lingkungan sekitar. Ditengah banguan yang terbuka terdapat lahan yang tidak diperkeras dengan pemberian vegetasi 2 buah pohon yang mengeskpresikan kesetangkupan yang tidak ganjil. Berlanjut ke area berkontur di bagian atas terdapat area Gunungsari Patrajaya, area ini berfungsi sebagai vantage point bagi pengunjung untuk menyaksikan view dan vista bangunan pengunjung dapat menyaksikan rumah-rumah warga kampung topeng. Berikutnya pengunjung diajak memasuki Area Jejer Sabrang \& Perang Brubuh yang terletak di tengah tapak dimana area ini merupakan klimak dari rangkaian jalur wisata dengan penutup rangkaian kegiatan berada di Area Bubaran yang merupakan area service dari kampong wisata topeng ini.

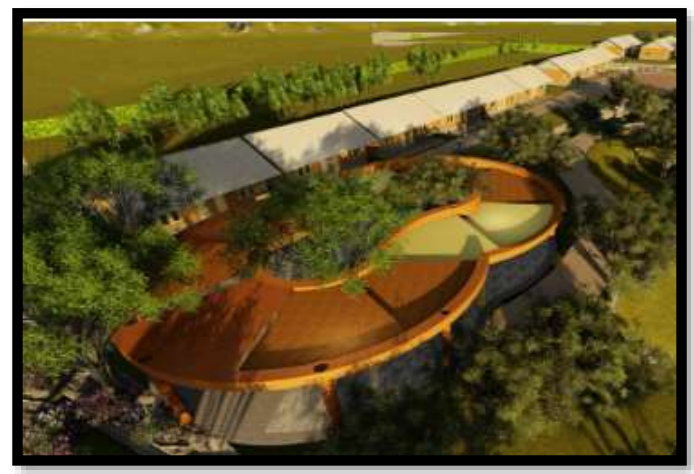

Gambar 10. Suasana Art Work Sanggar Tari \& Workshop Topeng

\section{Area Penerimaan (Introduction Space)}

Desain yang dikembangkan pada area penerimaan dari kampung Topeng Dusun Baran Tlogowaru ini diciptakan berupa pintu gerbang berbentuk umbul umbul yang terbuat dari bata preconstruction, yang berfunsi sebagai penanda atau signifier bahwa pengunjung telah memasuki kampung wisata topeng. Gerbang berbentuk umbul umbul dipilih dengan pertimbangan, untuk memberi ekspresi penyambutan memasuki kampung wisata topeng.

Umbul umbul juga merupakan suatu penanda bahwa terdapat suatu pusat kegiatan di dalam kampong wiata topeng Baran, Tlogowaru, Kota Malang. Keberadaan 2 buah umbul-umbul tersebut menggambarkan kesetangkupan, selain sebagai pengarah berupa batu yang diletakkan berseberangan dengan berjumlah genap dan berdiameter $20 \mathrm{~cm}$ menuju area selanjutnya. Tema yang diangkat pada welcome area dari kampung wisata topeng adalah nuansa tetembangan pengiring tari topeng mulai dari area gending giro yang memiliki makna awalan diikuti dengan tetabuhan yang mengiringi setiap zona yang ditata berupa orkestrasi gending-gending pengiring pertunjukan tari topeng malangan.

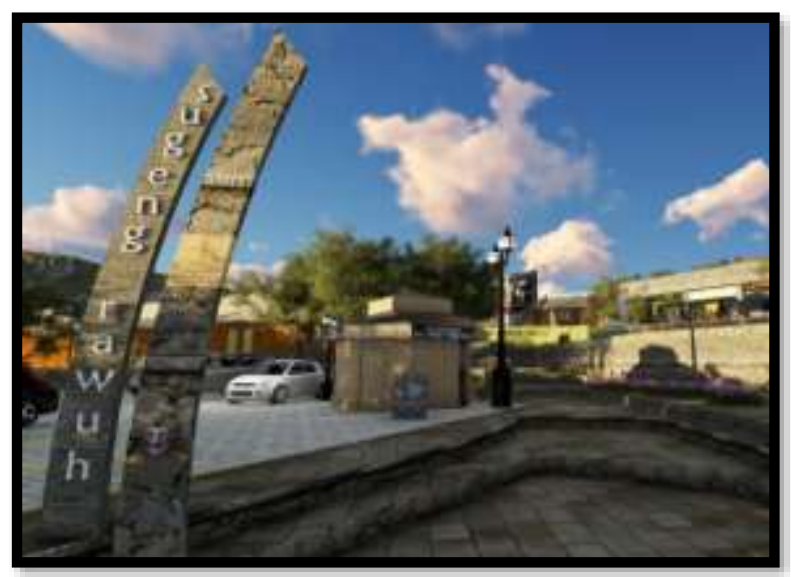

Gambar 11. Ekspresi gerbang /gapura pada area penerimaan yang dieksplorasi dari umbul-umbul

\section{Area Transisi dan Servis}

Pada kampung wisata topeng Dusun Baran Tlogowaru, didesain kehadiran dua area transisi, yakni Area Beskalan \& Area Patrajaya Gunungsari. Area Beskalan Lanang merupakan ruang peralihan yang memanjang dengan meletakkan beberapa sitting group di sepanjang area. Ruang Beskalan lanang ini 
merupakan perwujudan maskulinitas dan feminimitas yang melambangkan sifat kesetangkupan dari lambang cinta sejati oleh dua insan yang dilambangkan dengan peletakan 2 buah sitting group yang saling bersebrangan. Pada zona ini juga terdapat 8 buah sitting group dan masing masing memiliki diameter $125 \mathrm{~cm}$ dan maknanya apabila dikali kan (125x $8=1000) \quad$ maka akan mencapai 1000 yang memiliki makna kampung 1000 topeng

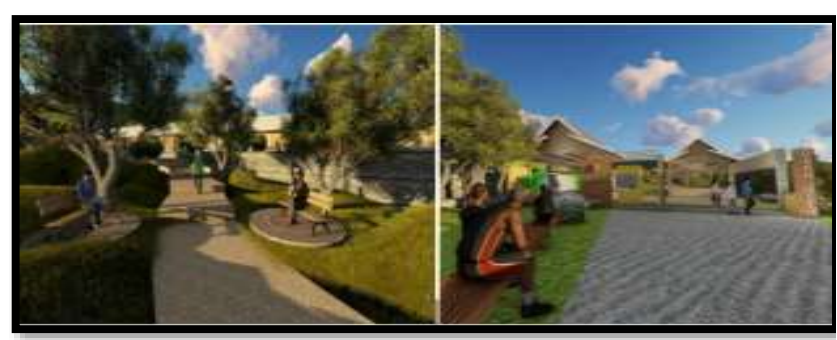

Gambar 12. Desain sequence suasana pada Area Transisi/Sitting Group dan Service Area

Pada area Patrajaya Gunungsari terletak di area perumahan kampung topeng di Dusun Baran, Tlogowaru, dalam area ini disajikan pemandangan rumah-rumah penghuni kampung topeng, area ini mengekspresikan simbol alam sadar \& alam bawah sadar yang menunjukkan spirit alam yang bermakna kehidupan, rumah sendiri adalah tempat tumbuhnya seseorang, dimana tempat ini digunakan sebagai tempat untuk bernaung, mengawali dan mengakhiri.

Area service terletak di letakkan pada bagian akhir dari sekuensi jalur wisata. Pada area service ini keberadaannya lebih difungsikan sebagai zona pelayanan untuk pengunjung. Tema yang diangkat pada area service diinterpretasikan dari pengakhiran orkestrasi dan dramaturgi ruang bubaran yang difungsionalisasikan sebagai tempat fasilitas-fasilitas pendukung dan pelengkap seperti fasilitas area cinderamata \& area makan minum. Fasilitas resto, dam area makan minum serta kios cinderamata didesain dengan tipologi bangunan yang sama, konsepnya ternaung dan terlindung secara terbuka dengan penataan massa bangunan yang terpisah. Bangunan pada area servis memiliki luasan yang berbeda, dan dielaborasi dari penggunaan bilangan genap disetiap ukurannya, hal ini mengekspresikan penggenapan dan memiliki arti tidak kurang maupun tidak ganjil. ukuran 6 × 10 m untuk area makan minum dan area cinderamata memiliki pelataran yang berukuran 4 x 10, apabila dijumlah memiliki nilai 100 yang memiliki arti kesempurnaan.

\section{Area Utama (Main Area)}

Dalam area utama terdapat fasilitas sitting group \& amphitheatre. Sebelum menuju area utama pola sirkulasi dibuat kontras agar terlihat bahwa seseorang akan memasuki area utama dengan mengubah bentuk linear menjadi berkelok sehingga terkesan kontras, area ini ditandai dengan area sitting group yang bejumlah dua buah yang menggambarkan kesetangkupan.

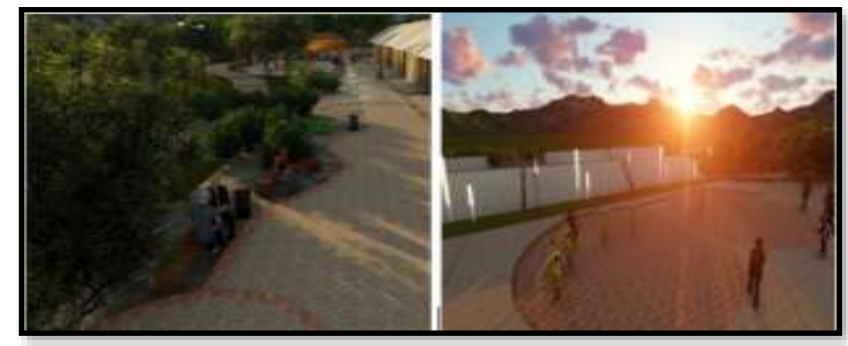

Gambar 13. Desain Area Sitting Group dan Main Area Kampung Topeng Baran Tlogowaru

Fasilitas amphitheatre ditampilkan dalam bentuk dua buah lingkaran, dimana setiap bagian memiliki diameter $600 \mathrm{~cm}$ yang menggambarkan 6 karakter utama dalam tokoh topeng malangan. Area ini juga dikelilingi oleh obor api \& air mancur yang mengekspresikan makna dari dua elemen yang saling bertolak belakang yang dianalogikan sebagai klimaks dari rangkaian cerita Pepanjian Topeng Malangan. Ada berbagai macam atraksi wisata yang bisa dipentaskan pada fasilitas amphitheater ini, seperti Tari topeng, kesenian jaranan dan live music yang bisa dinikmati oleh pengunjung pada fasilitas Amphitheatre Jejer Sabrang ini. Letaknya yang sentris berada di bagian tengah kampong topeng ini ditujukan untuk memberikan kemudahan orientasi dan keleluasaan visual bagi penikmat atau pengunjung dari segala arah.

\section{KESIMPULAN}

Kampung Topeng Malang di Dusun Baran, Kelurahan Tlogowaru, Kecamatan Kedungkandang, Kota Malang merupakan kawasan yang mempunyai nilai budaya dan kesenian topeng malangan. Potensi objek dan atraksi serta lanskap dusun yang berciri khas seni kriya topeng malangan di dusun tersebut 
layak untuk dijadikan sebagai salah satu tempat wisata budaya yang bernuansa budaya topeng malangan. Pengembangan desain untuk wisata budaya di Dusun Baran, Kelurahan Tlogowaru, Kecamatan Kedungkandang, Kota Malang direncanakan dengan konsep menjaga kelestarian budaya melalui pengembangannya sebagai kawasan wisata budaya dengan zona-zona pendukung wisata budaya tersebut yaitu zona penerimaan (introduction space - welcome area), zona transisi, zona pelayanan (service area) dan zona utama (main area), beserta sejumlah fasilitas pengisinya. Daya dukung kawasan wisata budaya ini relatif cukup memadai untuk tumbuh dan berkembang sebagai kampung wisata yang unik karena elaborasi tematiknya.

Hal-hal penting yang disarankan dandiusulkan untuk mendukung terwujudnya pengembangan kampung wisata topeng malangan ini adalah : (1). perlu adanya bantuan pemerintah daerah untuk mendukung, mengawasi dan konsistensi membangun dari pemerintah; (2) perlu bantuan dari penduduk/masyarakat setempat untuk mendukung, memelihara dan menjaga kualitas lingkungan serta mempertahankan budaya topeng malangan yang ada di kampung wisata ini; dan (3) perlu pelaku bisnis/swasta untuk mendukung berkembangnya perokonomiaan dan pendapatan masyarakat di kampung wisata topeng malangan ini supaya pengunjung dan para insvestor merasa nyaman dan tertarik ke kampung wisata ini.

\section{DAFTAR PUSTAKA}

Chiara JD, Kopplemen LE. 1994. Standar Perencanaan Tapak. Penerjemah: Januar Hakim. Jakarta (ID): Penerbit Erlangga. Terjemahan dari: Site Planning Standars.

Nurisjah S, Pramukanto Q, Siswantinah W. 2003. Daya Dukung Dalam Perencanaan Tapak. Bogor (ID) : Arsitektur Lanskap, FP IPB.

Subadyo, AT. 2011. Lanskap Spatial Arsitektural Desa Pakraman. Unmer Press.

Subadyo, AT. 2017. Pengelolaan Dampak Pembangunan Rumah Potong Hewan Ruminansia di Kota Batu. Jurnal Abdimas. Pengabdian Masyarakat, Universitas Merdeka Malang. Volume 2, Nomor 1, Desember 2017.

Wulandari RK. 2002. Perencanaan Lanskap Wisata Budaya Kampung Sade, di Lombok Tengah, Nusa Tenggara Barat [Tesis]. Bogor (ID): PPS IPB Bogor. 